Keiichi Muramatsu $\cdot$ Koichiro Ihara $\cdot$ Hiroshi Tanaka Shinya Kawai

\title{
Carpal instability in rheumatoid wrists
}

Published online: 14 November 2003

(C) Springer-Verlag 2003

\section{Rheumatol Int (2003): D0I s00296-002-0276-x}

The article was published online without the two illustrations and their captions. Figures 1 and 2 and their legends are given here.

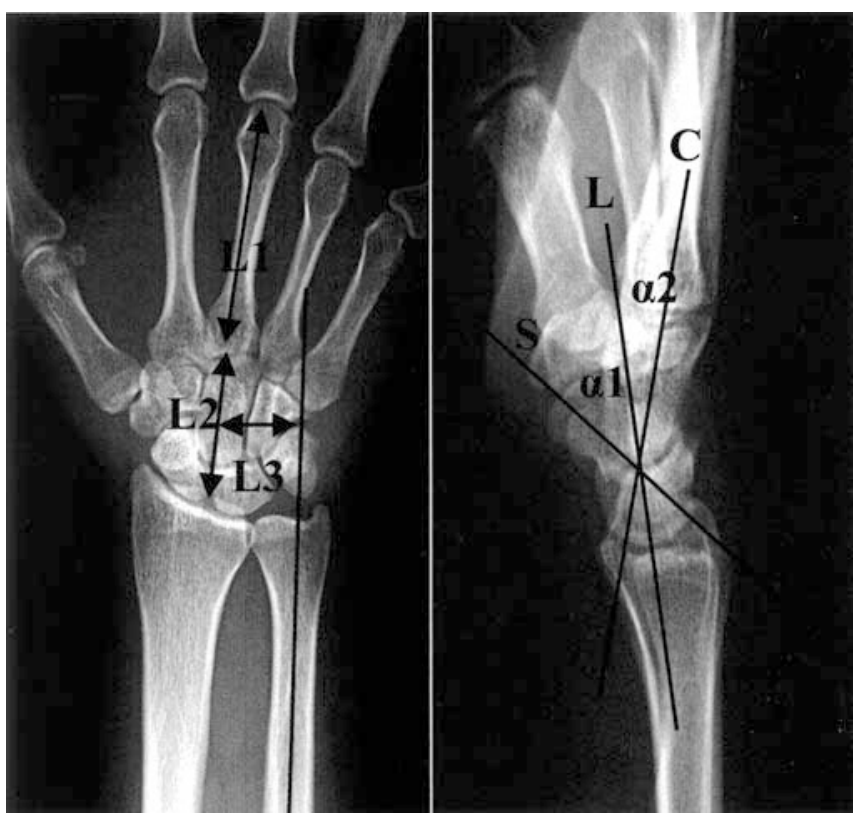

Fig. 1 Techniques of measurements of carpal alignment. Carpal height ratio $(\mathrm{CHR})=\mathrm{L} 2 / \mathrm{L} 1(\mathrm{n}=54 \pm 3 \%)$ [4]; ulnar translocation index $(\mathrm{UTI})=\mathrm{L} 3 / \mathrm{L} 1(\mathrm{n}=30 \pm 3 \%)[5]$; scapholunate angle $(\mathrm{SLA})=$ $\alpha 1 \quad\left(\mathrm{n}=46 \pm 15^{\circ}\right)$; capitolunate angle $(\mathrm{CLA})=\alpha 2 \quad\left(\mathrm{n}=0 \pm 15^{\circ}\right)$; scaphocapitate angle $(\mathrm{SCA})=\alpha 1+\alpha 1[6]$

The online version of the original article can be found at http:// dx.doi.org/10.1007/s00296-002-0276-x

K. Muramatsu $(\bowtie) \cdot$ K. Ihara $\cdot H$. Tanaka $\cdot$ S. Kawai Department of Orthopedic Surgery and Rheumatology, Yamaguchi University School of Medicine,

1-1-1 Minami-Kogushi, Ube, 755-8505 Yamaguchi, Japan

E-mail: muramatu@po.cc.yamaguchi-u.ac.jp

Tel.: + 81-836-222268

Fax: + 81-836-222267

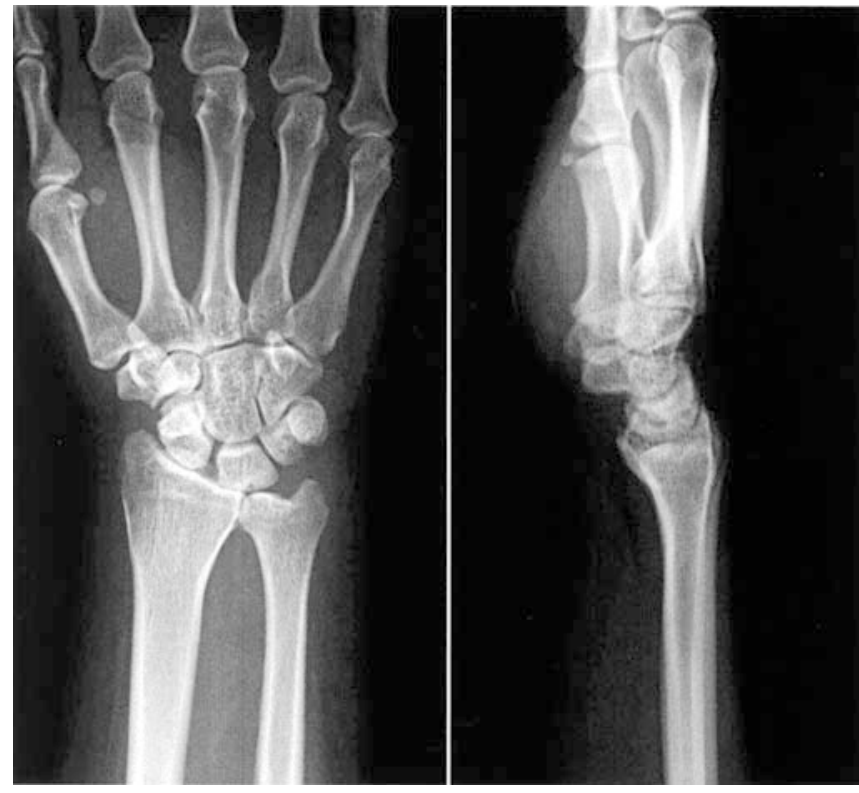

Fig. 2 A 40-year-old woman. Right wrist radiography revealed scapholunate dissociation combined with volar intercalated segmental instability pattern 